\title{
Review On: Medicinal Uses, Phytochemistry And Pharmacological Action Of The Plant Bauhinia Racemosa (Lam.).
}

\author{
K. A. Karande" , S. K. Attar, S. S. Jadhav, N. D. Gidde, K. V. Gaikwad, R. S. Mistry.
}

\section{Correspondence author:}

\section{Komal A. Karande*}

Department of Pharmaceutical Chemistry, Adarsh college of Pharmacy, Vita-415 311, Maharashtra.

\section{Email : komalkarande909@gmail.com}

\begin{abstract}
:
Herbal medicines are now attracting attention as potential sources to treat so many diseases or disorders. Plants have been used for medical purposes since the beginning of human history and are the basis of modern medicine. Bauhinia racemosa (Lam.) belongs to family Caesalpiniaceae, is a small deciduous tree with drooping branches. This plant grows in poor and very harsh climatic conditions the leaves and stem bark of the plant Bauhinia racemosa (Lam.) are usefull in headache, dysentery, diarrhoea, skin disease, fever and blood diseases. The plant reported to have antiulcer, antidiabetic, anticoagulant, hyperlipidemia, antitumor, antimicrobial, antioxidant, antianxiety, anthelmintic, analgesic, antipyretic, antihistaminic, anti-inflammatory, and hepatoprotective properties. The plant reported to have antiulcer, antidiabetic, anticoagulant, hyperlipidemia, antitumor, antimicrobial, antioxidant, antianxiety, anthelmintic, analgesic, antipyretic, antihistaminic, anti-inflammatory, and hepatoprotective properties. This review provides detailed information on plant Bauhinia racemosa (Lam.).
\end{abstract}

Keywords: Bauhinia racemosa (Lam.), herbal medicine, potential sources, caesalpiniaceae, 


\section{INTRODUCTION:}

Plants are used for medicinal purposes since from ancient time. The natural plants with traditional history were explored by researchers for their biological activity. A century ago most of the few effective drugs like aspirin (from willow bark), digoxin (from foxglove), quinine (from cinchona bark) and morphine (from opium poppy) were obtained from plants. ${ }^{[1]}$

Herbal medicines include plant-based medicines which are made from different plant parts like leaves, flowers or roots. Their medicinal uses differ from part to part. Different extraction methods are used for different chemical constituents. Both fresh and dried plant matter are used depending on the herb. ${ }^{[2]}$ The use of plants for healing purposes predates recorded history and forms the origin of much of modern medicine. ${ }^{[3]}$ Herbal medicines was practiced by ancient cultures in Asia, Africa, Europe And the America. The recent popularity in use of herbals can be tied to the belief that herbs can provide some benefit over and above allopathic medicine and allow users to feel that they have some control in their choice of medications. ${ }^{[4]}$ The indigenous people of Transkei depend on natural plant resources from the forests for the medicinal, cultural, religious and other needs. ${ }^{[5]}$ As herbal medicines are used by increasing numbers of people, pharmacists must be knowledgeable about their safety. ${ }^{[6]}$ Herbal medicines are also offer as a good remedies for age related disorders like memory loss, osteoporosis, immune disorders for which no any modern medicine is available. ${ }^{[7]}$

The human body consists of different types of cells. These cells grow and divide in a controlled way to produce more cells as they are required to body remains healthy. When cells become old or damaged, they die and they are replaced with new cells. However, sometimes this orderly process goes wrong. The genetic material [DNA] of a cell can become damaged, producing mutations that affect normal cell growth and division. When this happens, cells do not die when they should and new cells form when the body does not need them. The extra cells may form a mass of tissue called a tumor. ${ }^{[8]}$ Cancer is a hyperproliferative disorder that involve transformation, dysregulation of apoptosis, proliferation, invasion, angiogenesis and metastasis. Cancer causes more than 7 millions deaths per year worldwide more than HIV/AIDS, malaria and tuberculosis. ${ }^{[9]}$ This is the second most common disease after cardiac disorders leading to high rate of mortality in the world. In the upcoming year the number of cancer patient would increase 
in the emerging and underdeveloped countries up to $70 \%$ to become an issue of serious concern. In India liver, lungs, breast, rectum, colon and stomach cancers are frequently detected. ${ }^{[10]}$

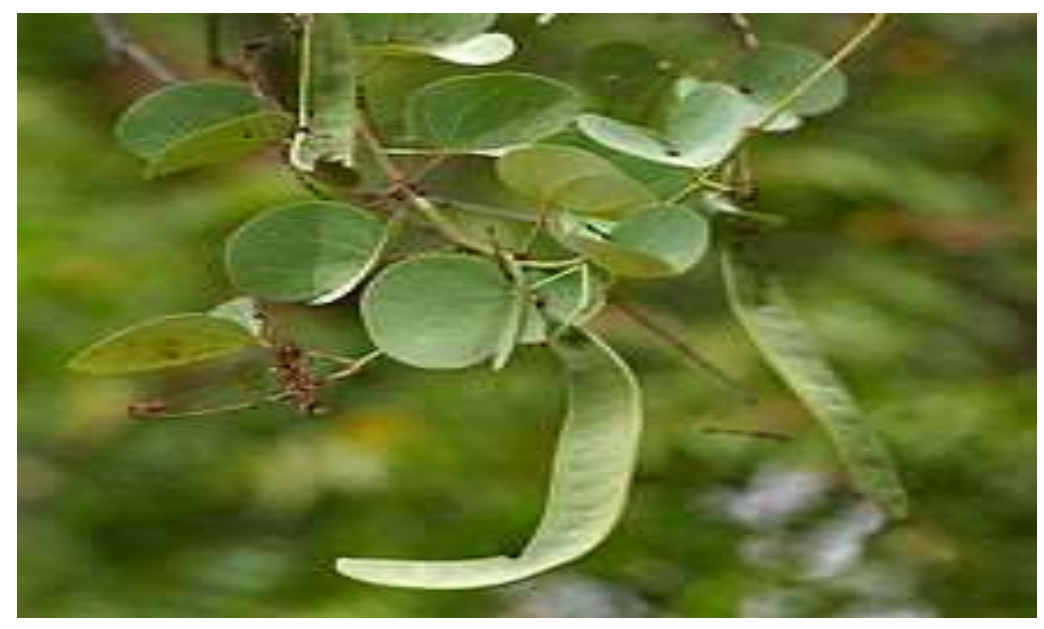

Fig.1.0 - Bauhinia racemosa (Lam.)

\section{Introduction to family Caesalpiniaceae:}

A family of dicotyledonous plants (sometimes considered to be a subfamily- Caesalpinioideae united with the subfamilies Papilionoideae and Mimosoideae in the family Leguminosae. The plants are mostly trees and shrubs with twicepinnate or simply pinnate leaves. The flowers are mainly irregular but in contrast to typical Leguminosae, not papilionaceous.

There are about 150 genera, comprising as many as 2,800 species. The plants occur mostly in the tropics and subtropics of both hemispheres. The genera Gleditschia and Cercis (which includes the Judas tree) are found in the USSR. Also under cultivation there are the carob and various ornamental species of the genera Cassia and Caesalpinia. Many species yield valuable wood (logwood) and various resins and medicinal substances. The fruits of some species are edible (tamarind, carob). 


\section{Characteristics of Caesalpiniaceae:}

It shows great variation in habit i.e., may be trees (Delonix regia, Tamarindus, Caesalpinia, Saraca indica, Cassia fistula, Bauhinia etc.), shrub, under shrubs or herbs. Besides this sometimes all types of plants occur in same genus e.g., Cassia fistula - tree; C: sophera-shrub; C. occidentalis - undershrub and C. tora - annual herb. Bauhinia vahlii is a woody climber. Roots are Tap and branched. Stem is Erect, woody, herbaceous or climbing, branched, glabrous or covered with prickles and spines (Parkinsonia). The leaves of Caesalpiniaceae are alternate, leaf base pulvinate, compound unipinnate (Cassia, Tamarindus), bipinnate (Delonix, Caesalpinia) or rarely simple; stipulate. In Bauhinia the leaf is deeply emarginate - perhaps due to the fusion of two leaflets. Flowers are Pedicellate, bracteate, zygomorphic, complete, hermaphrodite, slightly perigynous, pentamerous.

\section{Taxonomical classification of plant:}

Kingdom: Plantae

Sub kingdom: Tracheobionta

Division: Magnoliophyta

Class: Magnoliopsida

Sub class: Rosidae

Order: Fabales

Family: Caesalpiniaceae

Genus: Bauhinia

Species: racemosa

Vernacular name: Aapta 


\section{Synonyms:}

Bauhinia parviflora Vahl

Piliostigma racemosusm (Lam.) Benth.

Piliostigna racemosa (Lam.) Benth.

\section{Botanical Description:}

Bauhinia racemosa (Lam.) a small deciduous tree belonging to family Caesalpiniaceae, is a rare medicinal species of flowering shrub with religious significance. It is a small crooked tree with drooping branches that height is 3-5 metres (10-16 ft) tall. Flowers are white and appears in axillary or terminal racemes. March to June plant gets flowering. Fruit is a pod, oblong, compressed, often twisted and dark green. Bark is black and rough. Leaves are orbicular, bifolate and alternate distichous with entire margins.

\section{Geographical Distribution:}

It is native to tropical southeast asia. It is mostly present in lowland and drier forest type of north western south America, Bauhinia racemosa (Lam.) is very common in foothills up to $1000 \mathrm{~m}$ in India and Sri lanka. It is tropical dry thorn found in transects in the nilgiri landscape of Western Ghats in India.

\section{Chemical Constituents:}

Leaf: Five flavonols (kaempferol and quercetin) and two coumarins (Scopoletin and Scopolin) were also isolated from the leaves of the plant. The ethanol extract of Bauhinia racemosa (Lam.) leaves shows analgesic, antipyretic, anti-inflammatory, antispasmodic activities and antimicrobial activity.

Root: A new tetracyclic lupeol, betulin, $\beta$-sitosterol, and tetracyclic 2, 2-dimethyl chroman have been isolated from the roots. 
Stem bark: The stem bark of the plant is an astringent, used in the treatment of headache, fever, skin diseases, tumors, blood diseases, dysentery (Kirtikar and Basu, 1975). $\beta$-sitosterol and $\beta$ amyrin probably responsible for the popular use of the plant, were isolated from the stem bark of this plant.

Seed: The seed contains flavonoids, crude protein, and lipid.

Flower: The fresh flower buds of the plant showed antiulcer activity. Cytotoxicity against CA-9 $\mathrm{KB}$ in cell culture, as well as hypotensive and hypothermic activities has been reported from the hydroalcoholic extract of Bauhinia racemosa (Lam.).

Hard wood: The other phytoconstituent of Bauhinia racemosa (Lam.) have been isolated, chiefly includes tri-terpenoids ( $\alpha$-amyrin) and stilbenes (resveratrol) from the hardwood. ${ }^{[11]}$

\section{Traditional Uses:}

The plant Bauhinia racemosa (Lam.) belongs to the Caesalpiniaceae Family. It is popularly known as Sittacha (Tamil) and occurs frequently in India, Ceylon, China, and Timor. The stem bark of the plant is an astringent and is used in the treatment of headache, fever, skin diseases, tumors, blood diseases, dysentery, and diarrhea. Chemical constituents such as B-sitosterol and Bamyrin. probably responsible for the popular use of the plant, were isolated from the stem bark of this plant. Beside these compounds, at least five flavonols (kaempferol and quercetin) and two coumarins (scopoletin and scopolin) were also isolated from the leaves of the plant. Stilbene (resveratrol) was isolated from the heartwood of Bauhinia racemosa (Lam.). Pharmacological studies of the plant have revealed that the ethanol extract of Bauhinia racemosa (Lam.)leaves shows analgesic, antipyretic, anti-inflammatory, and antispasmodic activities, as well as antimicrobial activity. The fresh flower buds of the plant showed antiulcer activity. The antioxidant and hepatoprotective effects, as well as the antitumor and antioxidant status of Bauhinia racemosa (Lam.) against Ehrlich ascites carcinoma in Swiss albino mice are reported. $^{[12]}$ 


\section{Pharmacological Activity:}

Anti-oxidant: R.S. Kumar et. al the antioxidative activity of the methanolic extract of Bauhinia racemosa (Lam.) was determined by the ammonium thiocyanate method which measures the peroxide level during the initial stages of lipid oxidation. The antioxidant activity of methanolic extract of Bauhinia racemosa (Lam.) might be due to hydroperoxides, inactivation of free radicals or complex forming with metal ions, or combinations thereof. This good antioxidant activity of methanolic extract of Bauhinia racemosa (Lam.) might be attributed to the presence of phytochemicals such as flavonoids and biflavones. ${ }^{[12]}$

Analgesic: V. I. Borikar et. al studied, The analgesic activity of the stem bark of the Bauhinia racemosa (Lam.) plant in rats. weighing around 150-200g. Aqueous \& alcoholic extracts of dried stem bark of Bauhinia racemosa (Lam.). At 100, $200 \mathrm{mg} / \mathrm{kg}$ body weight were used in this study. Aqueous extract of Bauhinia racemosa (Lam.) stem bark at $200 \mathrm{mg} / \mathrm{kg}$ body weight produced significant analgesic activity in albino rats while at $100 \mathrm{mg} / \mathrm{kg}$ body weight did not produced significant analgesic activity. the analgesic activity of methanol extract, obtained from Bauhinia racemosa (Lam.) stem bark in rats significantly at the dose rate of 50, $100 \& 200 \mathrm{mg} / \mathrm{kg}$ which the evaluated by acetic acid-induced writhing and hotplate tests. the stem bark of Bauhinia racemosa (Lam.) possess analgesic activity in rats. ${ }^{[13]}$

Anti-microbial: Antimicrobial research always looks for new potent antimicrobial drugs from alternative sources. Medicinal plants proved to be a major source of new drug discovery. Gaurav Kumar et.al study that the Antimicrobial activity of the methanol and aqueous extract of the leaves of Bauhinia racemosa (Lam.). Both extracts showed antibacterial activity against E. coli, M. luteus and P. aeruginosa but not against Klebsiella pneumoniae and Staphylococcus aureus, whereas B. subtilis was inhibited by methanol extract but not by aqueous extract. Both extracts showed significant antifungal activity against C. albicans and Aspergillus niger. ${ }^{[14]}$

Anti-pyretic: El-Khatiba and Khaleel, studied the pharmacological activity of ethanolic extract from Bauhinia racemosa (Lam.) leaves related to antipyretic activity in yeast induced hyperpyrexia in rats. The aqueous and alcoholic extracts of Bauhinia racemosa (Lam.) significantly reduced the temperature suggesting that extracts might have antagonized prostaglandins and produce its effect. ${ }^{[15]}$ 
Anti-cancer: Md. Azizur Rahman et.al reported, the methanolic extract of Bauhinia racemosa (Lam.) possess potent cytotoxic activity against a cancer cell line. The cytotoxic activity and apoptotic effects of methanolic extract of Bauhinia racemosa (Lam.)were evaluated by methylthiazolyl-tetrazolium assay and 4',6-diamidino-2-phenylindole staining test respectively on HeLa, a cancer cell line. Methanolic extract of Bauhinia racemosa (Lam.)exposure of HeLa cells significantly decreased the cell viability $(p<0.001$, IC50 =80 ug/ml) comparable to that of tamoxifen $(p<0.001$, IC50 = 48 ug/ml) in a concentration dependent manner. It also lead to the depolarization of mitochondria and induced production of ROS initiating apoptotic effect in a concentration dependent manner. ${ }^{[16]}$

Anti-histamine: Rahman Md. Azizur et. al study that the ethanolic extract of Bauhinia Racemosa (Lam.) leaves inhibited clonidine-induced catalepsy in male Swiss albino mice at a dose of $50 \mathrm{mg} / \mathrm{kg}$, administered intraperitoneally. But, there was no effect on haloperidol-induced catalepsy suggesting that the inhibition is through an antihistaminic action and that there is no role of dopamine. It has role in the treatment of asthma. ${ }^{[1]}$

Anti-ulcer: The use of plant flavonoids from Bauhinia racemosa (Lam.) as antiulcer remedies and for the prevention and treatment of peptic ulcer. V. I. Borikar et.al reported, the antiulcer activity of aqueous and alcoholic extracts of the stem bark of Bauhinia racemosa (Lam.). ${ }^{[18]}$

Anthelmintic: Helminthiasis, or worm infestation, is one of the most prevalent disease and one of the most serious public health problems in the world. Whole plant of Bauhinia racemosa (Linn.) have anthelmintic activity. Tekeshwar kumar et. al study the Aqueous, ethanolic and petroleum ether extracts from the whole plant of Bauhinia racemosa (Linn.) were investigated for their anthelmintic activity against Pheretima posthuma. Various concentrations (50, 75 and $100 \mathrm{mg} / \mathrm{ml}$ ) of each extracts were tested in the bioassay, which involved determination of time of paralysis and time of death of the worms. ${ }^{[19]}$

Anti-diabetic: The leaves of medicinal plant Bauhinia racemosa (Lam.) with different pharmacological activities were subjected to phytochemical screening and assessment of their in vitro inhibitory potential with porcine pancreatic amylase enzyme to treat and management of diabetes. Bhimraj gawade, Mazahar Farooqui studied that the phytochemical screening of leaves 
extract reveals the presence of carbohydrate, alkaloids, saponin, glycosides, steroids, tannins, flavonoids, triterpenoid, and phenolic compounds. The ethanol extract reported inhibition of amylase enzyme activity at IC50 value $61.72 \pm 0.3 \mathrm{~g} / \mathrm{mL}$ and acarbose as a standard drug at IC50 value $28.07 \pm 0.02 \mathrm{~g} / \mathrm{mL}^{[20]}$

\section{Conclusion:}

From this review we concluded that, the plant Bauhinia racemosa (Lam.) is very important plant which have wide applications in medicinal system. All parts of the plant like root, leaves, stem, flower and seed possess pharmacological activity. The plant Bauhinia racemosa (Lam.) have chemical constituents as flavonoids, crude protein, and lipid, tri-terpenoids ( $\alpha$-amyrin), stilbenes (resveratrol), tetracyclic lupeol, betulin, $\beta$-sitosterol, and tetracyclic 2, 2-dimethyl chroman. This active chemical constituents imparts variety of medicinal uses to the plant that is antioxidant, antiulcer, anticancer, antihistamine, antidiabetic, anthelmintic, antimicrobial, antipyretic and analgesic.

\section{References:}

1. Vickers A, Zollman C. Herbal medicine. British Medical Journal. 1999; 319 (7216); 1050-1053.

2. "What is Herbal Medicine". The National Institute of Medical Herbalists. Available fromwww.nimh.org.uk.

3. Vickers A, Zollman C. Herbal medicine. Western journal of medicine. 2001; 175(2); 125128.

4. Michael J Wargovich, Cynthia Woods, Destiny M Hollis, Marry E Zander. Herbal cancer prevention and health. The journal of nutrition. 2001; 131(11); 3034S-3036S.

5. Rama B Bhat, Thomas V Jacobs. Traditional herbal medicine in Transkei. Journal of ethanopharmacolpgy. 1995; 48(1); 7-12.

6. Joseph I Boullata, Angela M Nace. Safety issues with herbal medicine. Pharmacotherapy: The journal of human pharmacology and drug therapy. 2000; 20(3); 257-269.

7. Ved P Kamboj. Herbal medicine. Current science. 2000; 78(1); 35-39.

8. Shumaila Arshad, Maryam Sharif, Ayesha Naseer. A mini review on cancer and anticancer drugs. Indo American journal of Pharmaceutical sciences. 2016; 3(11); 
1383-1388.

9. Javad Tavakoli, Solaleh Miar, Mohammad Majid Zadehzare, Hossein Akbari. Evaluation of Effectiveness of Herbal Medication in Cancer Care: A Review Study. Iranian journal of cancer prevention. 2012; 5(3); 144-156.

10. N. V. Badgujar, Kinnari n. Mistry, P. N. Chudasama and J. S. Patel. In vitro Antioxidant and cytotoxic effects of Vitex negundo, Lantana camara, Bauhinia variegata and Bauhinia racemosa on human cancer cell line. Indian journal of pharmaceutical sciences. 2017; 79(3); 431-437.

11. Vishal Soni, Arvind Kumar, Jha Jaya, Dwiwedi Priyanka, Soni. Traditional uses, phytochemistry and pharmacology of Bauhinia racemosa Lam - a review. Korean Journal Publishing service. 2015; 5(4); 24-24.

12. R.S. Kumar, T. Sivakumar, R.S. Sunderam, M. Gupta, U.K. Mazumdar, P. Gomathi, Y. Rajeshwar, S. Saravanan, M.S. Kumar, K. Murugesh and K.A. Kumar. Antioxidant and antimicrobial activities of Bauhinia racemosa L. stem bark. Brazilian journal of medical and biological research. 2005; 38(7); 1015-1024.

13. V. I. Borikar, C.R Jangde, D.S. Rekhe and Preety Philip. Study of Analgesic activity of Bauhinia racemosa lam in Rats. Veterinary World. 2009; 2(4);135-136.

14. Gaurav Kumar, L. Karthik and K. V. Bhaskara Rao. Phytochemical composition and in vitro antimicrobial activity of Bauhinia racemosa lamk (caesalpiniaceae). International journal of Pharmaceutical sciences and research. 2010; 1(11); 51-58.

15. V.I. Borikar, C.R Jangde, Preety Philip, D.S. Rekhe and S.K Atole. Study of Antipyretic Activity of Bauhinia Racemosa (Lam.) in Rats. Veterinary World. 2009; 2(6); 217-218.

16. Md. Azizur Rahman, Juber Akhtar, Sahabjada, Md. Arshad. Evaluation of cytotoxic potential and apoptotic effect of a methanolic extract of Bauhinia Racemosa (Lam.) against a human cancer cell line, HeLa. European journal of integrative medicine. 2016; 8(4); 513-518.

17. Rahman Md. Azizur, Kamal Mehnaz, Hussain Arshad, Arif Muhammad, Khushtar Mohd. Phytochemistry and pharmacology of traditionally Used tropical medicinal plant Bauhinia racemosa (Lam.). The pharma research: An International Journal of Pharmacy Research. 2015;13(1); 26-41. 
18. V. I. Borikar, C.R Jangde, Preety Philip and D.S. Rekhe. Study of Antiulcer Activity of Bauhinia racemosa Lam in rats. Veterinary World. 2009; 2(6); 215-216.

19. Tekeshwar Kumar, Amit Alexander, Ajazuddin, Dhansay Dewangan, Junaid Khan and Mukesh Sharma. Investigation of in-vitro anthelmintic activity of Bauhinia racemosa linn. Journal of ap plied pharmaceutical science. 2011; 1(2); 73-75.

20. Bhimraj gawade, Mazahar Farooqui. Screening of phytochemicals and in vitro antidiabetic activity of Bauhinia Racemosa (Lam.) Leaves. Asian journal of pharmaceutical and clinical research. 2018; 11(6); 190-3. 